\title{
ANALISIS KANDUNGAN FORMALIN PADA BAKSO TUSUK YANG BEREDAR DI BEBERAPA SEKOLAH DASAR DI KOTA MANADO
}

\author{
Ary Muhatir ${ }^{1)}$, Sri Sudewi ${ }^{1)}$, Henki Rotinsulu ${ }^{1)}$ \\ ${ }^{1)}$ Program Studi Farmasi FMIPA UNSRAT Manado, 95115
}

\begin{abstract}
Formalin is a solution which made from $37 \%$ formaldehyde in water which is commonly used as preservative for cosmetic products and various types of non-food industrial materials. The use of formalin as a preservative in food is very dangerous for health. The purpose of this study was to determine the presence of formalin found in skewered meatballs circulating in several elementary schools in the city of Manado. Sampling was done in Malalayang Elementary School (A), State Elementary School 6 Manado (B), State Elementary School 9 Manado (C) and State Elementary School 29 Manado (D). In a qualitative test, Nash reagents were used to determine the presence of formalin in the sample. Nash reagent was used to indicate the presence of Formalin content in a sample marked with a change in color to yellow. The results of this study showed that twelve samples of skewers from four elementary schools in Manado City did not contain formalin or safe from formalin use.
\end{abstract}

Keywords: Formalin, Formaldehyde, Skewered Meatballs, Nash Reagent, Qualitative Analysis

\begin{abstract}
ABSTRAK
Formalin merupakan larutan yang dibuat dari $37 \%$ formaldehida dalam air yang umumnya digunakan sebagai bahan pengawet produk kosmetik dan berbagai jenis bahan industri non makanan. Penggunaan formalin sebagai bahan pengawet pada makanan sangat berbahaya bagi kesehatan. Tujuan penelitian ini yaitu untuk mengetahui keberadaan formalin yang terdapat pada bakso tusuk yang beredar di beberapa Sekolah Dasar di Kota Manado. Pengambilan sampel dilakukan di SD Negeri Malalayang (A), SD Negeri 6 Manado (B), SD Negeri 9 Manado (C) dan SD Negeri 29 Manado (D). Pada pengujian kualitatif digunakan pereaksi Nash untuk mengetahui adanya formalin pada sampel. Pereaksi Nash ini digunakan untuk menunjukkan adanya kandungan Formalin pada sampel yang ditandai dengan perubahan warna menjadi kuning. Hasil penelitian ini menunjukkan bahwa dua belas sampel bakso tusuk dari empat Sekolah Dasar di Kota Manado tidak mengandung formalin atau aman dari penggunaan formalin.
\end{abstract}

Kata Kunci: Formalin, Formaldehida, Bakso Tusuk, Pereaksi Nash, Analisis Kualitatif 


\section{PENDAHULUAN}

Makanan cepat saji adalah makanan yang tersedia dalam waktu cepat dan siap disantap. Makanan cepat saji telah menjadi kebiasaan makan bagi generasi muda baik pelajar, mahasiswa, maupun para karyawan yang merupakan bagian terbesar dari populasi masyarakat indonesia saat ini. Sisi praktis dan rasanya yang lezat mungkin menjadi alasan sebagian besar masyarakat yang memilih mengonsumsi makanan cepat saji. Salah satu jenis makanan cepat saji yang popular adalah bakso karena harganya yang relatif murah sehingga dapat terjangkau oleh masyarakat luas (Sekarwati, 2016).

Jajanan merupakan makanan favorit bagi anak-anak sekolah khususnya anak sekolah dasar. Selain murah, jajanan juga sangat praktis untuk disantap saat anak SD sedang beristirahat di sekolah. Jajanan yang dijajakan di sekolahan sangat beragam, sebagai contoh bakso, mie, agar-agar, jelly dan lain-lain. Namun, jajanan yang sering ditemui di sekolah-sekolah tanpa disadari dapat membahayakan kesehatan tubuh karena di dalam makanan tersebut terdapat zat-zat yang berbahaya (Sekarwati, 2016).

Tingkat keamanan dari pangan jajanan anak sekolah (PJAS) masih rendah. PJAS sendiri adalah pangan siap saji yang ditemui di lingkungan sekolah dan secara umum dikonsumsi oleh sebagian besar anak sekolah (Sekarwati, 2016). Hasil penelitian Sekarwati (2016), menyatakan bahwa semua bakso yang diperjual belikan di Sekolah Dasar Negeri wilayah kecamatan Depok Sleman tidak mengandung formalin. Namun, hasil ini belum bisa dinyatakan bahwa semua makanan cepat saji yang diperjual belikan di Sekolah Dasar aman dari penggunaan formalin.

Formalin merupakan jenis bahan tambahan berbahaya yang masih sering digunakan secara bebas oleh pedagang atau produsen pangan yang tidak bertanggung jawab. Larangan penggunaan formalin sebagai bahan tambahan makanan telah tercantum dalam Permenkes RI No.33 tahun 2012, tentang Bahan Tambahan Pangan (BTP) (Suryadi dkk, 2010).
Penggunaan formalin pada makanan sangat berbahaya bagi kesehatan, akibat yang bisa ditimbulkan dari penggunaan formalin ialah luka bakar pada kulit, iritasi pada saluran pernapasan, reaksi alergi dan bahaya kanker. Menurut peraturan Menteri Kesehatan RI No.1168/Menkes/Per/X/1999 tentang Bahan Tambahan Makanan. Peraturan tersebut secara jelas mengatakan bahwa formalin sebagai bahan kimia yang dilarang di gunakan dalam makanan. Formalin sangat berbahaya jika terhirup, mengenai kulit, dan tertelan (BPOM, 2003).

Pada metode spektrofotometri ada berbagai macam pereaksi yang dapat digunakan untuk uji formalin dalam makanan, antara lain pereaksi $\mathrm{KMnO}_{4}, \mathrm{~K}_{2} \mathrm{Cr}_{2} \mathrm{O}_{7}, \mathrm{FeCl}_{3}$, asam kromatofat, Schiff's, Nash, Fehling dan $\mathrm{AgNO}_{3}$. Pereaksi yang dipilih adalah pereaksi Nash. Pereaksi Nash adalah pereaksi yang tidak berwarna dan dapat digunakan untuk analisis kualitatif dan kuantitatif formalin. Setelah direaksikan dengan formalin maka akan diperoleh perubahan warna dari larutan jernih tak berwarna menjadi larutan berwarna kuning (Harmita, 2004).

Berdasarkan hal-hal diatas mendorong penulis untuk melakukan penelitian tentang analisis kandungan formalin pada makanan bakso tusuk yang di jajakan di beberapa Sekolah Dasar Kota Manado. Analisis yang dilakukan yaitu identifikasi dengan menggunakan metode spektrofotometri UVVis.

\section{METODOLOGI PENELITIAN Waktu dan Tempat Penelitian}

Penelitian ini dilaksanakan pada bulan Februari sampai Maret 2019 di Laboratorium Lanjutan Kimia Farmasi, Program studi Farmasi Fakultas Matematika dan Ilmu Pengetahuan Alam, Universitas Sam Ratulangi Manado.

\begin{abstract}
Alat
Alat-alat yang digunakan dalam penelitian ini yaitu alat-alat gelas erlenmeyer, tabung reaksi, mikro pipet (Ecopipet), labu ukur, gelas ukur, timbangan analitik (aeADAM), batang pengaduk, pisau, destilasi
\end{abstract}


Volume 8 Nomor 3 Agustus 2019

uap, spektrofotometri Uv-Vis (Shimadzu 00780) dan komputer pengolah data (Acer Aspie ES 11).

\section{Bahan}

Bahan yang digunakan adalah formaldehida $37 \%$, ammonium asetat, asam asetat glacial, $\mathrm{H}_{3} \mathrm{PO}_{4} 85 \%$, asetil aseton, Aquades dan bakso tusuk yang diperoleh dari pedagang pada beberapa Sekolah Dasar di Kota Manado.

\section{Pengambilan Sampel}

Sampel bakso diambil dari pedagang bakso di empat Sekolah Dasar yang berbeda yang berada di Kota Manado. Dimana setiap Sekolah Dasar diambil pada tiga penjual yang berbeda pula.

\section{Prosedur Penelitian}

\section{Preparasi Sampel}

Sebanyak 10 gram pada masing-masing sampel bakso, dipotong-potong kemudian dimasukkan ke dalam labu destilat, ditambahkan $50 \mathrm{~mL}$ aquades, kemudian diasamkan dengan menggunakan $1 \mathrm{~mL} \mathrm{H}_{3} \mathrm{PO}_{4}$ $85 \%$. Labu destilat dihubungkan dengan pendingin dan didestilasi. Hasil destilat ditampung dalam labu ukur $50 \mathrm{~mL}$.

\section{Pembuatan Pereaksi Nash}

Ditimbang 150 gram ammonium asetat dan dilarutkan kedalam $700 \mathrm{~mL}$ aquades. Ditambahkan $3 \mathrm{~mL}$ asam asetat glacial dan 2 $\mathrm{mL}$ asetil aseton lalu ditambahkan aquades hingga volume tepat $1000 \mathrm{~mL}$.

\section{Uji Sensitivitas Pereaksi Terhadap Larutan Standar Formalin}

Larutan standar formaldehid diencerkan menjadi 0,$037 ; 3,7 ; 370$ ppm. Masing-masing hasil pengenceran dimasukkan kedalam enam tabung yang berbeda, kemudian ditambahkan pereaksi uji. Pengujian dilakukan pada rentang konsentrasi formalin yang menunjukkan hasil positif dan negatif terhadap pereaksi.

\section{Uji Kualitatif}

Uji kualitatif dilakukan dengan menggunakan pereaksi uji yaitu pereaksi nash. Dipipet $1 \mathrm{~mL}$ hasil destilat dalam tabung reaksi, kemudian ditambahkan 2,5 $\mathrm{mL}$ pereaksi nash, jika terbentuk warna kuning hal ini berarti positif mengandung formalin.

\section{HASIL DAN PEMBAHASAN}

\section{Pengambilan Sampel}

Dua belas sampel bakso tusuk diambil dari empat Sekolah Dasar di Kota Manado yaitu SD Negeri Malalayang (A), SD Negeri 6 Manado (B), SD Negeri 9 Manado (C) dan SD Negeri 29 Manado (D) pada tanggal 22 februari 2019. Sampel dari tiap-tiap Sekolah Dasar diambil pada tiga penjual yang berbeda.

\section{Uji Sensitivitas Pereaksi Terhadap Larutan Standar Formalin}

Pengujian sensitivitas pereaksi terhadap larutan standar formalin dimaksudkan untuk mengetahui batas konsentrasi formalin yang masih dapat terdeteksi oleh pereaksi uji.

Pengujian sensitivitas pereaksi uji dilakukan terhadap larutan formalin konsentrasi 0,037 ; 3,7; dan 370 ppm.

Tabel 1. Pengujian Sensitivitas Pereaksi Nash

\begin{tabular}{cc} 
Larutan Standar & Perubahan Warna \\
\hline $370 \mathrm{ppm}$ & Kuning \\
$3,7 \mathrm{ppm}$ & Kuning Pucat \\
$0,037 \mathrm{ppm}$ & Kuning Transparan \\
\hline
\end{tabular}

Berdasarkan hasil yang diperoleh, pereaksi Nash dapat mendeteksi formalin hingga konsentrasi terkecil yaitu 0,037 ppm. Sensitivitas pereaksi Nash dapat menunjukan hasil yang baik pada konsentrasi 0,$037 ; 3,7$; dan 370 ppm. Namun, pada konsentrasi 0,037 ppm warna yang dihasilkan tidak terlalu jelas yaitu kuning transparan

\section{Analisis Kualitatif Formalin Pada Sampel}

Analisis kualitatif dilakukan untuk menyatakan ada tidaknya formalin dalam suatu bahan yang diuji. Namun, uji kualitatif tidak dapat menunjukkan jumlah kadar formalin dalam bahan tersebut. Analisis kualitatif yang paling mudah untuk dilakukan yaitu dengan cara menambahkan zat kimia 
Volume 8 Nomor 3 Agustus 2019

(pereaksi) tertentu pada bahan yang diduga mengandung formalin, sehingga dihasilkan suatu perubahan warna yang khas (Widyaningsih dan Erni, 2006).

Pada proses preparasi sampel, dilakukan proses ekstraksi sampel dengan cara metode destilasi menggunakan alat destilasi uap. Destilasi merupakan suatu metode pemisahan bahan kimia berdasarkan perbedaan kecepatan atau kemudahan menguap (volatilitas) bahan. Metode destilasi uap dilakukan karena formaldehid merupakan senyawa yang berbentuk gas dan bersifat sangat volatil atau mudah menguap. Dalam proses penyulingan, campuran zat dididihkan sehingga menguap, dan uap yang dihasilkan kemudian

didinginkan kembali ke dalam bentuk cairan. Pemilihan pelarut merupakan salah satu faktor yang menentukan keberhasilan proses ekstraksi. Pelarut yang digunakan dalam proses ekstraksi ini adalah pelarut polar yaitu aquades.

Sebelum dilakukan proses destilasi, sepuluh gram pada masing-masing sampel bakso dihaluskan dengan cara dicincang menggunakan pisau. Penghalusan sampel dilakukan untuk memperluas permukaan sampel, karena luas permukaan sangat mempengaruhi proses ekstraksi. Semakin luas permukaan sampel, maka akan semakin mudah untuk memisahkan formalin dari sampel. Selanjutnya sampel dimasukkan ke dalam labu destilat, lalu ditambahkan $50 \mathrm{~mL}$ aquades, kemudian diasamkan dengan $1 \mathrm{~mL}$ $\mathrm{H}_{3} \mathrm{PO}_{4} \quad 85 \%$ dan dihomogenkan. Tujuan penambahan $\mathrm{H}_{3} \mathrm{PO}_{4} \quad 85 \%$ yaitu untuk mendegradasi sampel sehingga formalin yang terdapat dalam sampel dapat dipisahkan.

Pengujian kualitatif pada penelitian ini digunakan pereaksi Nash untuk mengetahui adanya formalin pada sampel. Pereaksi Nash dapat memberikan spektrum serapan berwarna bila direaksikan dengan formaldehid. Campurannya dengan formaldehid dapat memberi serapan berwarna kuning terang. Semakin kuning warna larutan yang didapat maka semakin besar konsentrasi yang terdapat dalam analit.
Tabel 2. Hasil pengujian kualitatif sekolah A

\begin{tabular}{ccc}
\hline Sampel & Warna & Keterangan \\
\hline A1 & Bening & Negatif \\
A2 & Bening & Negatif \\
A3 & Bening & Negatif \\
\hline
\end{tabular}

Tabel 3. Hasil pengujian kualitatif sekolah B

\begin{tabular}{ccc}
\hline Sampel & Warna & Keterangan \\
\hline B1 & Bening & Negatif \\
B2 & Bening & Negatif \\
B3 & Bening & Negatif \\
\hline
\end{tabular}

Tabel 4. Hasil pengujian kualitatif sekolah C

\begin{tabular}{ccc}
\hline Sampel & Warna & Keterangan \\
\hline $\mathrm{C} 1$ & Bening & Negatif \\
$\mathrm{C} 2$ & Bening & Negatif \\
$\mathrm{C} 3$ & Bening & Negatif \\
\hline
\end{tabular}

Tabel 5. Hasil pengujian kualitatif sekolah D

\begin{tabular}{ccc}
\hline Sampel & Warna & Keterangan \\
\hline D1 & Bening & Negatif \\
D2 & Bening & Negatif \\
D3 & Bening & Negatif \\
\hline
\end{tabular}

Hasil yang didapat, semua sampel bakso yang telah di analisis menunjukkan hasil negatif atau tidak terjadi perubahan warna menjadi kuning yang merupakan indikator adanya formalin dalam sampel. Hal ini dapat dilihat dari warna yang dihasilkan yaitu bening. Penelitian ini menunjukkan dua belas sampel bakso tusuk yang diambil dari empat Sekolah Dasar di Kota Manado yaitu SD Negeri Malalayang (A), SD Negeri 6 Manado (B), SD Negeri 9 Manado (C) dan SD Negeri 29 Manado (D) tidak mengandung formalin atau bebas dari penggunaan formalin.

Uji kuantitatif pada penelitian ini tidak dilanjutkan karena semua sampel yang diambil tidak teridentifikasi adanya kandungan formalin.

\section{KESIMPULAN}

Berdasarkan hasil penelitian analisis kualitatif menggunakan Pereaksi Nash menunjukkan bahwa dua belas sampel bakso tusuk yang diambil dari empat Sekolah Dasar di Kota Manado yaitu SD Negeri Malalayang (A), SD Negeri 6 Manado (B), SD Negeri 9 Manado (C) dan SD Negeri 29 Manado (D) 
PHARMACON- PROGRAM STUDI FARMASI, FMIPA, UNIVERSITAS SAM RATULANGI,

Volume 8 Nomor 3 Agustus 2019

tidak mengandung formalin. Hal ini berarti, bakso tusuk pada keempat Sekolah Dasar tersebut aman dari penggunaan formalin. Uji kuantitatif pada penelitian ini tidak dilanjutkan karena semua sampel yang diambil tidak teridentifikasi adanya kandungan formalin.

\section{SARAN}

1. Diharapkan kepada penjual bakso tusuk agar senantiasa tidak menggunakan bahan berbahaya formalin dalam pembuatan bakso tusuk.

2. Sebaiknya dilakukan penelitian terhadap bakso tusuk di tempat lain untuk mengetahui ada tidaknya penggunaan formalin pada bakso tusuk yang diperjual belikan.

\section{DAFTAR PUSTAKA}

Badan Pengawas Obat dan Makanan. 2003. Mengenal Formalin. BPOM, Jakarta.

Harmita. 2004. Petunjuk Pelaksanaan Validasi Metode dan Cara Perhitungannya. Artikel Majalah Ilmu Kefarmasian. Vol. 1 No. 3. Departemen Farmasi FMIPA-UI, Jakarta.

Refwalu, H. M., J. A. Rorong, S. Sudewi. 2016. Analisis Kandungan Formalin Pada Berbagai Jenis Daging di Pasar Swalayan Kota Manado. Pharmacon.Vol. 5 No. 4. UNSRAT, Manado.

Sekarwati, N. 2016. Kajian Kandungan Formalin Pada Bakso Tusuk Yang Dijual di SD Negeri Wilayah Kecamatan Depok Sleman Yogyakarta. Jurnal Kesehatan Masyarakat. Vol. 9 No. 01. STIKES Wirahusada Yogyakarta, Yogyakarta.

Suryadi, H., M. Kurniadi., Y. Melanie. 2010. Analisis Formalin Dalam Sampel Ikan dan Udang Segar Dari Pasar Muara Angke. Majalah Ilmu Kefarmasian. VII (3): 16-31. Universitas Indonesia, Jakarta. 